International Review of Research in Open and Distance Learning (c)

ISSN: $1492-3831$

Vol. 1, No. 1 (June 2000)

\title{
Editorial
}

Peter S. Cookson

Athabasca University

irrodl@athabascau.ca

I extend a warm welcome to you as a reader of this inaugural issue of The International Review of Research in Open and Distance Learning (IRRODL). In this, my first editorial, I explain the meaning of the journal's name, purpose, content, and structure. I also explain the theme of the articles in this initial issue and express appreciation for the many people whose support has been instrumental in converting IRRODL from an idea to reality.

\section{What's in a Name?}

The aim of this journal is to live up to its name:

- International. IRRODL welcomes manuscripts relevant to open and distance learning from prospective authors throughout the world. Available without cost to anyone anywhere with an Internet connection, its primary intent is to serve an international audience.

- Review. As well as original work, the journal welcomes manuscripts that present systematic reviews of existing literature on open and distance learning theory, research, and practice in open and distance learning.

- Research. The journal welcomes not only manuscripts that feature systematic inquiry, but also articles on theory and best practice that have implications for research.

- Open and Distance Learning. Both distance learning and distance teaching may be regarded as essential sub-sets of the more inclusive term distance education. Despite its ambiguities, it was decided to have the title of this journal refer to distance learning as a synonym for distance education, defined as organized educational activities in which there is a physical or temporal separation between the learner and an educational agent. One particular kind of learning, open learning, refers to learning or education for which efforts are made to minimize constraints to learner participation. As with distance education, this term encompasses what has been variously referred to as distributed learning, flexible learning, online education, web-based education, independent learning, correspondence instruction, etc. 


\section{Purpose of this Journal}

The purpose of this refereed, interactive, online journal is to contribute and disseminate to practitioners and scholars worldwide scholarly knowledge in each of three areas: theory, research, and best practice in open and distance learning. Because our aim is for IRRODL to become the premier international journal of open and distance learning, we seek high quality submissions in each of these three areas. In harmony with the open learning philosophy that distance education should serve to remove barriers to those who, given their geographical location, previous level of schooling, or other life circumstances would otherwise not be able to access distance education opportunities, subscriptions are free to individuals. Regardless of geographical location, anyone connected to the Internet will have free access to the journal.

\section{Content}

Despite its title, The International Review of Research in Open and Distance Learning is intended to be a journal in which readers can inform themselves about distance education developments in theory, research, and best practice. Our aim is to have all three elements present in every issue. Some articles will stress one of the elements more than the other two. Other articles will combine two or three elements. Ideally, the collection of articles selected for each issue will convey to readers an overall sense of balance among all three elements.

Theory. Articles that focus on theory will highlight plausible or empirically determined principles offered to explain various distance education phenomena. There are numerous ways to categorize theory. One way is indicated in the terms: idiothetic versus nomothetic. Because of the predominantly applied nature of the field of open and distance learning, most theory in open and distance learning - when it is articulated - tends to be idiothetic, that is intended to explain the circumstances of single cases. There are relatively few examples of nomothetic theory, i.e., theory intended to explain phenomena in multiple cases. Articles in IRRODL that stress theory should enable readers to see how the theory relates to the existing distance education literature and to gain new levels of understanding about the nature and interrelationships among specific distance education phenomena. Such articles should clearly articulate the implications of the theory offered for research, improved practice and/or further theory development.

Research. Authors are invited to submit for publication well-written reviews of the theoretical and research literature on specific topics as well as original research reports of systematic data collection, analysis and interpretation. Both quantitative and qualitative research are acceptable. The choice of which type of research to conduct is dictated by the kinds of questions driving the study,

International Review of Research in Open and Distance Learning 
the nature and availability of the data, and the means to collect and interpret the data. These will vary from study to study. Often studies will combine both types of research analyses. Any type of research - as long as it has been conducted systematically in a responsible and defensible manner - will be considered for publication in IRRODL. Articles that consist of either literature reviews or reports of original research should clearly articulate implications for theory development, improved practice, and/or further research. Not generally acceptable for publication would be articles based on exploratory research, i.e., research conducted to generate insights that can inform subsequent research to be conducted with more methodological rigor.

Best Practice. Authors are invited to submit for publication manuscripts that focus on "best practice," highlighting the experience of individuals and/or institutions engaged in the process of distance learning/teaching, from which distance educators in other settings may gain insights regarding how they might improve their own performance. "Best practice" articles may consist of detailed descriptions of particular open and distance learning activities. Alternatively, they might present cogent arguments or proposals for enhancement and/or expansion of existing open and distance learning activities. Featured "best practices" may include learners' experiences, methods, techniques, delivery systems, policies, issues, etc. If an article is based on conclusions that have been reached after careful observations that, although not conducted with the rigor of a formal research project, nevertheless appear to be well grounded, it may well be considered for inclusion in this category. To increase the usefulness and generalizability of their reports, authors should explain how the best practices described in their articles relate to the existing distance education literature and clearly articulate the "so what" for distance education theory, research, and/or practice in a wide variety of cultural, national, and institutional settings.

\section{Structure}

With the possible exception of "theme issues," each issue of IRRODL will contain the following sections:

- "Main section": scholarly articles, refereed, featuring theory, research, and or best practice in open and distance learning

- "Notes": containing information designed to provide distance educators with news concerning developments regarding research, practice, additions to the literature, and conferences related to open and distance learning.

- "Web Conference": For 30-45 days following release of each issue, readers will have the opportunity to carry on online conversations, via computermediated communication, with article authors and other readers.

International Review of Research in Open and Distance Learning 


\section{Explanation of the Theme for Number 1}

Addressing the theme "The Problems and the Promise: Into the New Century," distinguished and internationally recognized scholars have written the six articles that appear in this first issue. Two articles address each of three areas: theory, research and best practice in open and distance learning. Reflecting the different perspectives of their authors, these articles review both the record and prospects of advancement of open and distance learning in each of these areas. Although not exhaustive in their respective reviews, these articles will inform both those who are seasoned veterans as well as those who are newcomers to the field of open and distance learning. Collectively, the authors in this first issue present many insights for the advancement of theory, research, and practice in open and distance learning.

Clearly theory can inform both research and practice. Research can confirm and refine theory and, at the same time, provide guidance for improved practice. When reflected upon, practice, in turn, can inform theory and inspire research. Despite the generally recognized value of these interrelationships, it is surprising how little those who are engaged in the provision of education and training at a distance draw on the theoretical foundations of the field. It is also surprising how seldom systematic and rigorous research is conducted to test, confirm and refine theory. The challenge facing the field of open and distance learning is to be aware of the theoretical foundations of the field, conduct research that will enable expansion of those foundations, and to thus engage in the more knowledgeable and effective practice of open and distance learning. The content of this first issue of IRRODL constitutes one response to that challenge.

\section{A Word of Appreciation}

The establishment of IRRODL and the launching of this initial issue have resulted from a significant team effort. For that reason I take this opportunity to express appreciation to the Executive Group of Athabasca University - Canada's Open University - for their vision in deciding to make the journal an institutional priority; the Associated Editors whose advice and assistance have been crucial to the determination of the policies and structure of the publication. I especially commend our Managing Editor, Ms. Jan Thiessen, without whose extraordinary "second," "third" and even "fourth mile" service, IRRODL would still be on the drawing board. I express appreciation to the Editorial Board and Consulting Editors who from different countries on every continent have agreed to lend us a hand in this enterprise. I acknowledge the assistance of the moderators and assistant moderators of the three computer conferences that follow the release of this first issue. I am grateful, too, to Mike Sosteric and his assistants who have been responsible for establishing a technical "home" for IRRODL with the International Consortium for the Advancement of Academic 
Publication.

Finally, I express appreciation to you, our reader. Your comments in response to this initial issue and your manuscript contributions are most welcome. I look forward to hearing from you.

Citation Format

Cookson, Peter S. (2000) Editorial. International Review of Research in Open and Distance Learning: 1, 1. http://www.icaap.org/iuicode?149.1.1.11

International Review of Research in Open and Distance Learning 